SLAVICA BOŠTJANČIČ RAKAS, Ph.D. ${ }^{1}$

(Corresponding author)

E-mail: slavica.bostjancic@institutepupin.com

MIRJANA STOJANOVIĆ, Ph.D. ${ }^{2}$

E-mail: m.stojanovic@sf.bg.ac.rs

${ }^{1}$ University of Belgrade

Mihailo Pupin Institute

Volgina 15, 11060 Belgrade, Serbia

2 University of Belgrade

Faculty of Transport and Traffic Engineering

Vojvode Stepe 305, 11000 Belgrade, Serbia
Information and Communication Technology

Original Scientific Paper

Submitted: 20 Apr. 2018

Accepted: 4 Apr. 2019

\title{
A CENTRALIZED MODEL FOR ESTABLISHING END-TO-END COMMUNICATION SERVICES VIA MANAGEMENT AGENTS
}

\begin{abstract}
This paper presents a centralized approach for establishing end-to-end communication services via management agents. The main proposal is the modular architecture of the third-party based Service Establishment Agent (SEA). The SEA manages inter-provider service negotiation process with per-domain management agents through an appropriate signaling agent. It also receives and interprets end-toend service requests, selects inter-domain paths, performs mapping of service classes among domains on the path, and evaluates conformance of the offered service level with the required one. It allows implementation of different algorithms for the aforementioned functions as well as their selection and combination according to the predefined management policies. Simulation results show that the proposed model significantly outperforms the distributed model in terms of service negotiation times. In the prototype development process, a policy-based solution for mapping of service classes was implemented. The performance evaluation shows that processing requirements for handling multiple service requests are modest, while benefit of the SEA approach is the lack of need to build long-term consensus among providers about technical choices for achieving network interconnection. The SEA architecture is completely independent of the quality of service mechanisms available in particular domains.
\end{abstract}

\section{KEY WORDS}

centralized management; inter-provider; quality of service; service establishment;

\section{INTRODUCTION}

In the past decade, we have witnessed a great expansion of the Internet Protocol (IP) technology in the information and communication infrastructure of industrial sectors like electric power systems, transportation systems, petrochemical industry, water and waste-water treatment [1]. Nowadays, the proliferation of Big Data, Internet of Things, Cloud Computing and Mobile Computing pose additional requirements regarding end-to-end (E2E) quality of service (QoS) and network interconnection. Many access networks may exist using various wired or wireless technologies, while new service providers can enter and exit the market every day. Innovative or new solutions are needed regarding cross-domain policy enforcement to achieve easier management and higher security of QoS-enabled services [2].

For the purpose of inter-provider QoS delivery, relations between the providers can be defined using two basic groups of models: the distributed and centralized ones. Hybrid approaches, as a combination of the basic models, are also possible. Service is established after the negotiation process, which results in $\mathrm{E} 2 \mathrm{E}$ Service Level Agreement (SLA). SLA defines all technical, financial and legal aspects of a particular service between two parties: the provider and the customer. Inter-provider SLAs are usually wholesale and they describe aggregate traffic between domains.

The distributed models are usually denoted as bilateral or cascade [3, 4]. Providers negotiate bilateral SLAs only with their direct neighbours, on the basis of their own QoS capabilities and QoS capabilities of their neighbouring domains. Static or dynamic concatenation of the bilateral SLAs between every pair of domains on the path is needed to provide E2E QoS. The distributed approach is widely addressed regarding standardization and research efforts in terms of automated inter-provider cooperation [5]. In spite of high scalability, this model suffers from several inherent drawbacks. First, service negotiation time increases with the number of transit domains. This highly affects the network resource utilization, because resource reservation should be performed during negotiation. Second, if different QoS architectures are applied in the domains on the path, mapping of service classes should be performed at domains boundaries. Third, the problem of objective and meaningful measurement of overall performance may appear. Finally, when 
the traffic is crossing more than two domains, there is a risk that the E2E QoS requirements may not be achieved.

The cooperative approach tends to mitigate the aforementioned drawbacks [4]. It is a generalized distributed approach, where a group of providers enter into partnership that is called federation [6]. Federation members agree on service specifications, common set of service classes and tools for performance monitoring, responsibilities of the providers and charging mechanisms. The service is usually sold by the domains providing access services. This approach requires the specification of a common framework for interconnected networks to provide harmonization of QoS mechanisms implemented in different domains.

The centralized approach assumes that a single party (either a provider or a trusted third party) performs service negotiation on behalf of domains under its authority. Thus, a single party is responsible for E2E service definition, service class mappings, inter-provider measurements and management of business processes. Benefits of such an approach refer to avoiding the need for direct negotiation among providers or re-engineering of their networks.

Increasing computational requirements are the main driving force towards centralized solutions at the network control plane [7]. For example, programmable paths that support service differentiation can rely on the agent-oriented approach [1]. Programmable agents might simplify fault diagnostics, reduce human intervention and improve network autonomy. Centralized service management is also applicable in a federated cloud environment $[8,9]$.

The centralized approach assumes that the 3P agent has complete overview of each domain under its authority, which can be critical if a provider denies sharing the required data for commercial or strategic reasons. To overcome this problem, a hybrid approach is possible, where such domains are not under the authority of the 3P agent. Hence, the 3P agent should be responsible for making bilateral or cooperative agreements with such providers, on behalf of its subordinate domains.

This paper presents a centralized model for establishing inter-provider QoS-enabled services via a trusted third-party (3P) agent. The main contribution is the proposal of a modular architecture of the Service Establishment Agent (SEA), which performs functions for interpretation of service requests, selection of $\mathrm{E} 2 \mathrm{E}$ paths, class mapping in every domain on the path, as well as matching conformance between the offered and the required service levels. The SEA manages service negotiation process with per-domain management agents through an appropriate QoS signalling agent. Another contribution refers to the analysis of signalling requirements of QoS negotiation process, assuming a generalized transaction-oriented signalling protocol. Finally, we developed the SEA prototype, and evaluated its performance in terms of processing time and CPU utilization, when handling simultaneous E2E service requests.

The rest of the paper is organized as follows: Section 2 surveys the related work; Section 3 proposes the SEA architecture and describes its modules and their interrelations; Section 4 contains the analysis of signalling requirements starting from a single signalling transaction, and followed by an in-depth simulation study of the two realistic Internet topologies; Section 5 describes the SEA prototype development by presenting the overall software structure and performance evaluation; Finally, Section 6 concludes the paper.

\section{RELATED WORK}

The functional model addressed in [4] assumes service negotiation for a group of domains via a trusted 3P agent, which connects with the group members at various points. This agent is responsible for the definition of E2E service, choice of metrics, mapping of service classes, measurements and business processes translation. The 3P agent can also sell the service and take part in the revenue.

Two centralized models are proposed and evaluated in [3]. The first one assumes service exchange entity that coordinates service negotiation for aggregate traffic in a group of domains that constitute the $\mathrm{E} 2 \mathrm{E}$ path. A hierarchical organization of multiple service exchange entities is proposed to improve scalability. The second one is the hub model, which assumes that one domain communicates with all other domains that constitute the E2E path during service negotiation process. Similarly, a distinction between fully centralized and per-provider centralized models is made in [10] and [11]. Fully centralized model is implemented through a third party called Facilitator, while per-provider centralized model assumes that the role of the Facilitator is taken by one of the service providers in the group. In both cases, service offers can be available prior to service request (push method) or generated upon the request for service (pull method).

A policy-based negotiation model is proposed in [12], assuming that negotiation process is divided into sub-negotiations with internal or external agents. Negotiation protocol, the associated policy language and the policy engine based on the model are also described.

The centralized, 3P-based approach is also explored in the context of ubiquitous consumer wireless environment [13]. The architectural concept of the trusted 3P-based management system assumes a hierarchical organization of $3 \mathrm{P}$ agents at the international, national and regional levels. In [14], the open 
access to network resource management (through application programming interfaces) in the IP Multimedia Subsystem (IMS) has been proposed to facilitate third-party agents to dynamically control QoS parameters on the established multimedia sessions.

An approach for logically centralized control and management of large networks via a set of physically distributed set of decision controllers has been proposed in [15]. This approach allows customization of the centralization level according to the scalability, fault-tolerance and responsiveness requirements of the underlying network.

A general structure of the service specification form, which contains technical parameters related to a particular service request, is proposed in [16]. Relying on such a general form, an efficient algorithm for per-domain service class selection has been proposed and evaluated. The algorithm runs in two stages: first, per-domain QoS requests are prepared, and second, the most appropriate class in each domain is selected by determining the closest match between the required and the offered service level.

3P-based algorithms for dynamic class mapping are also proposed in [17] and [18]. Both of them assume that the 3P agent collects providers' offers regarding performance metrics and interconnection costs for all classes in their domains. The first algorithm applies the integer programming optimization model to assure E2E QoS guarantees [17]. Per-domain class selection is then performed based on the exact fulfilling of QoS requirements and minimizing costs. The second algorithm uses the goal programming optimization model to control QoS mapping parameters coupled with E2E service requirements, and also takes into account interconnection costs [18]. This solution allows certain deviation from QoS requirements to achieve a tradeoff between QoS fulfilment and costs.
Most of the previous proposals dealt either with the model basics or with specific algorithms for certain negotiation tasks. The main motivation for this work was to propose the entire, flexible 3P-based architecture for E2E service establishment that meets the following objectives:

- Support of different algorithms for performing specific tasks in the negotiation process, e.g. path selection, mapping of service classes among domains and QoS conformance evaluation;

- Coexistence of multiple algorithms for the aforementioned tasks, and their selection and combination according to the predefined management policies;

- Independence of the QoS architectures implemented in individual domains that are under the 3P authority, and preservation of particular intra-domain QoS solutions.

\section{FUNCTIONAL ARCHITECTURE}

The inter-domain management functions are supposed to be performed by the authorized, trusted intermediary, i.e. the 3P agent as illustrated in Figure 1. Each domain has its own management entity, namely, the Domain Management Agent (DMA), which is responsible for intra-domain management. Hence, the 3P agent actually represents a proxy server for DMAs. The 3P agent is logically central, meaning that it can be implemented on multiple server instances in a redundant manner, thus enhancing its reliability and scalability.

Signalling is needed to dynamically exchange relevant information between the $3 \mathrm{P}$ agent and each DMA. The 3P agent can be either collocated with one of the DMAs or located independently of DMAs under its authority. In both cases, the 3P agent and DMAs constitute an overlay network, which carries signalling

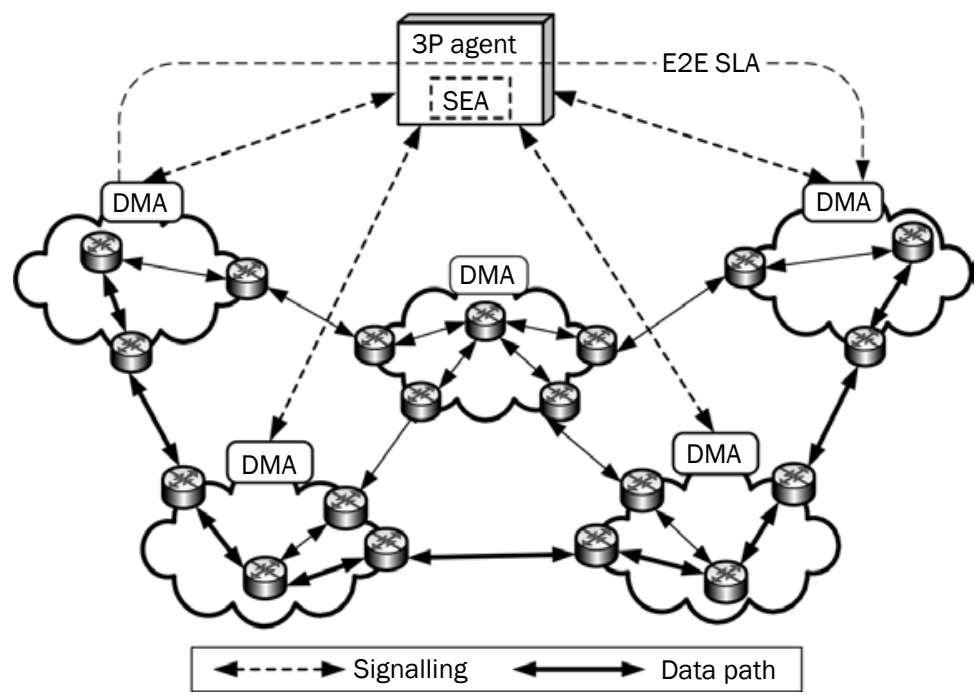

Figure 1 - Centralized service establishment via $3 P$ agent 
information. Since signalling is path-decoupled, protocols like Common Open Policy Service (COPS), the widespread Simple Network Management Protocol (SNMP) and various proprietary protocols can be applied.

A general layered architecture [19] of the 3P management agent is assumed, which consists of business management, service management and network management layers that together make use of signalling agent to communicate with domains management agents. Service management encompasses service establishment, provisioning and termination.

Service is set up through the SEA whose proposed architecture is depicted in Figure 2. The 3P agent maintains the set of global resource state tables, which contain information about topology, routing, domains capabilities, and resource usage. These tables need to be updated on a regular basis, through signalling between every DMA and the 3P agent.

The negotiation process begins with an E2E service request from the initiating DMA.

Signalling agent implements the appropriate QoS signalling protocol for the exchange of messages with DMAs, regarding service requests, configuration, updates, etc.

SEA consists of the following six modules: Request interpreter and policy selector, Path provider, Class mapper, QoS conformance evaluator, Decision maker, and SLA creator.

Request interpreter and policy selector is responsible for the extraction of the required E2E performance metrics (delay, jitter, packet loss rate) and selection of the set of appropriate management policies from the
Policy repository. This repository is a database with relevant sets of operating rules concerning business, service and network management processes. The policy is selected according to some specific administrative rules and resource state.

Path provider selects the path between the source and destination domains from the set of available paths, according to specific routing policy, security policy, or some other administrative policy. Different routing schemes are supported, depending on the selected routing policy. In other words, Path provider can rely on the routing information obtained from the underlying domains, e.g., to support routing with Border Gateway Protocol (BGP) or it can implement some centralized QoS routing scheme [16]. A centralized control for path selection might be very suitable for the promising software-defined networking (SDN) paradigm that can provide for data delivery paths and at the same time optimize the resource usage and reduce the network operation complexity [20]. Additionally, specific security policy can be taken into account in the process of path selection. Certainly, Path provider should update the inter-domain routing information on the regular basis. Information about the selected path is forwarded to the Class mapper.

Once the path is specified, Class mapper performs two tasks: (1) allocation of per-domain performance impairment budgets, and (2) class selection. The overall impairment budget is an upper bound of the allowed E2E performance impairment for metrics such as delay, jitter and packet loss rate. The first task implements the policy for dividing this overall budget among domains on the path [21, 22]. The second task

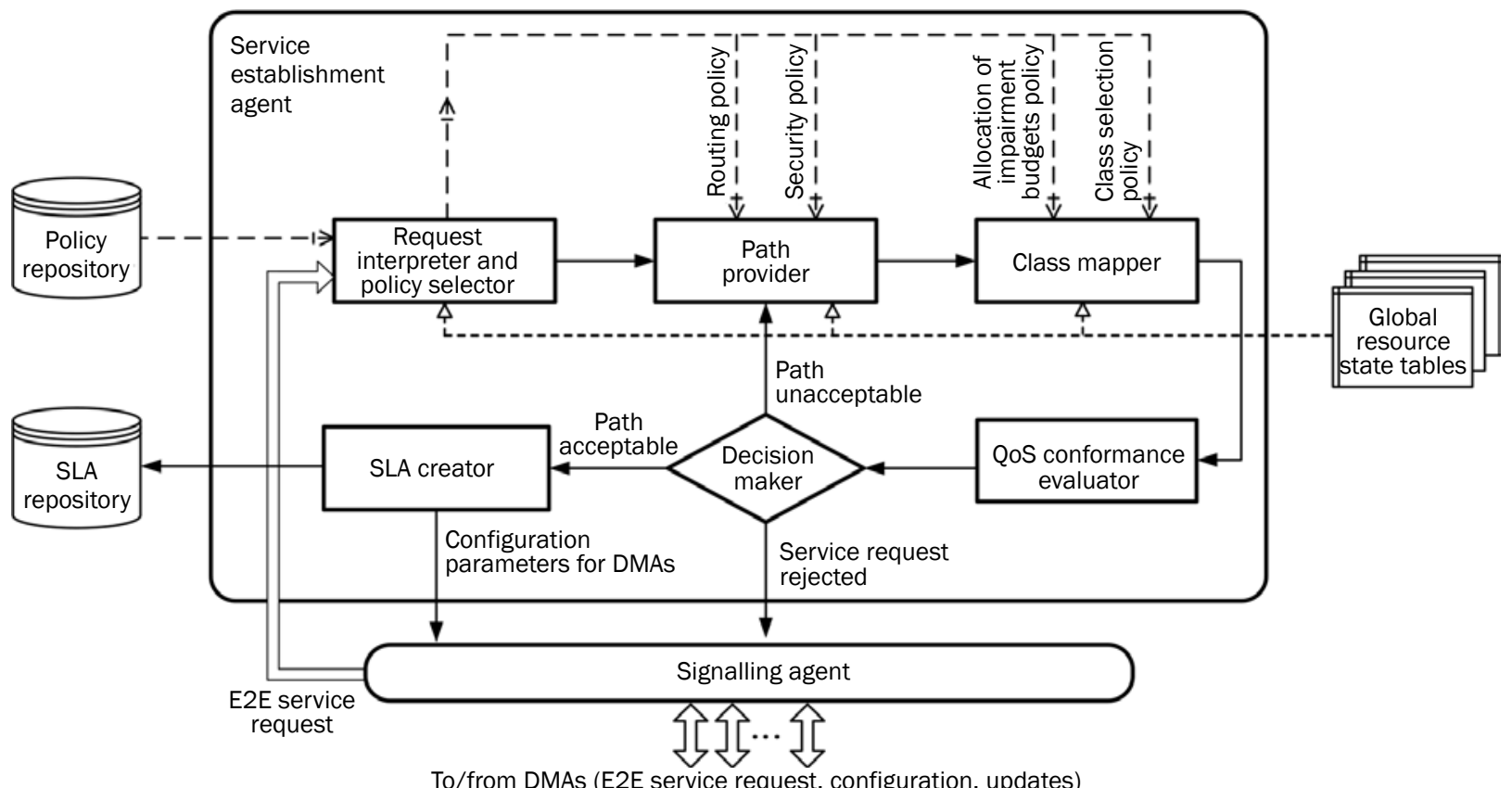

Figure 2 - Functional architecture of SEA 
solves the problem of different definition and specification of service classes, which might be implemented in domains on E2E path. Different static and dynamic policies are applicable for the selection of the most suitable class in every domain [16, 17, 18, 23].

After class mapping QoS conformance evaluator is activated. This entity first determines the conformance of the offered E2E QOS with the requested one according to some predefined criteria $[16,17,18]$. Second, it checks whether each domain on the path fulfils the required QoS objectives.

Decision maker further decides whether the path is acceptable based on factors like E2E QoS fulfilment and other predefined administration requirements, i.e. resource utilization, costs, projected revenue, etc. If the path is acceptable, SLA creator is activated. It prepares the configuration parameters and forwards them to the Signalling agent, which sends appropriate signalling messages to the corresponding DMAs. Further, it builds the SLA and stores it in the SLA repository. Otherwise, service can be renegotiated by analysing another E2E path, if available from Path provider. Service request is rejected if there are no more available paths.

\section{ANALYSIS OF QOS SIGNALLING REQUIREMENTS}

\subsection{Single signalling transaction}

Let us observe a group of $N$ administrative domains that are under the authority of the $3 \mathrm{P}$ agent. $\mathrm{SLA}_{i j}$ represents the unidirectional E2E contract between the source domain $i$ and the destination domain $j,(i, j=1$, $2, \ldots, N)$. The overall number $S$ of E2E agreements is:

$$
S=\sum_{i=1}^{N} \sum_{j=1}^{N} s_{i j}, i \neq j
$$

where $s_{i j}$ represents the number of active agreements between the initiating domain $i$ and the destination domain $j$. If there is exactly one unidirectional agreement between each pair of domains then $S=N(N-1)$.

QoS signalling protocols rely on the query-response paradigm. For the purpose of the analysis, an abstract protocol model is supposed, with two types of messages that constitute a single transaction, namely, the Request (Req) and the Response (Resp). The exchange of signalling messages, assuming a successful single transaction, is illustrated in Figure 3.

The initiating domain management agent (DMA $i)$ generates the appropriate SLA request $\left(\operatorname{Req}_{i, 3 \mathrm{P}}\right)$ and sends it to the $3 \mathrm{P}$ agent. The $3 \mathrm{P}$ agent then creates appropriate configuration requests for each DMA on the path $\left(R e q_{3 \mathrm{P}, i+1}, \ldots, R e q_{3 \mathrm{P}, j}\right)$ and simultaneously sends them to the corresponding DMAs. After collecting all

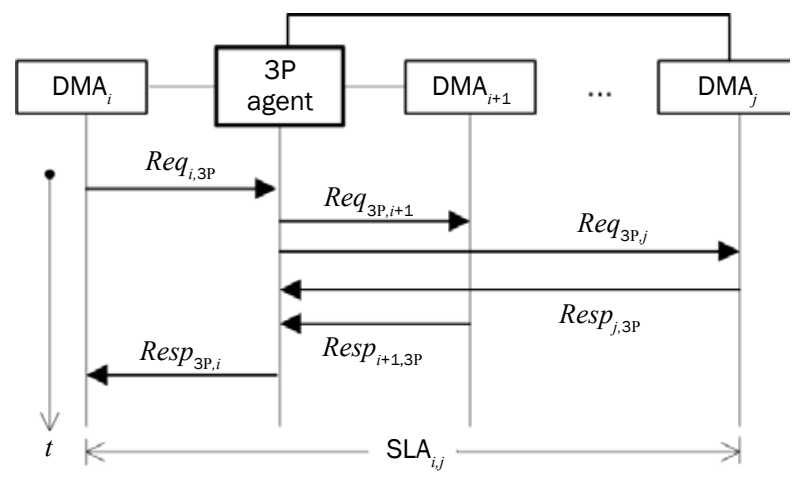

Figure 3 - The single signalling transaction via $3 P$ agent

responses $\operatorname{Resp}_{i+1,3 \mathrm{P}}, \ldots, \operatorname{Resp}_{j^{\prime} 3 \mathrm{P}}$, the 3P agent notifies the initiating DMA about the service establishment, through message $\operatorname{Resp}_{3 \mathrm{P}, i}$.

Suppose that $\tau_{\text {req }}$ and $\tau_{\text {resp }}$ are times needed to generate, transmit and process the signalling messages Request and Response, respectively. Both, $\tau_{\text {req }}$ and $\tau_{\text {resp }}$ are determined as the sum of propagation delay $\tau_{\text {prop }}$, and processing delay $\tau_{\text {proc }}$. Processing delay refers to the time needed in network elements to process signalling message, including queuing delays. Service negotiation time between domains $i$ and $j$, $\tau(i, j)$ is:

$$
\begin{aligned}
& \tau(i, j)=\tau_{\text {req }}(i, 3 \mathrm{P})+\tau_{\text {resp }}(3 \mathrm{P}, i) \\
& +\max \left\{\tau_{\text {req }}(3 \mathrm{P}, k)+\tau_{\text {resp }}(k, 3 \mathrm{P})\right\}_{i+1 \leq k \leq j}
\end{aligned}
$$

where $\tau_{r e q}(i, 3 \mathrm{P})$ corresponds to the transmission and processing of the message $\operatorname{Req}_{i, 3 \mathrm{P}}$ from Figure 4 , while $\tau_{\text {resp }}(3 \mathrm{P}, i), \tau_{\text {req }}(3 \mathrm{P}, k)$ and $\tau_{\text {resp }}(k, 3 \mathrm{P})$ correspond to messages $\operatorname{Resp}_{3 \mathrm{P}, i}, \operatorname{Req}_{3 \mathrm{P}, k}$ and $\operatorname{Resp}_{k, 3 \mathrm{P}}$, respectively, with $k=i+1, \ldots, j$. The signalling processing complexity is transferred to the $3 \mathrm{P}$ agent, i.e. the component $\tau_{r e q}(i, 3 \mathrm{P})$. DMAs perform simple processing of configuration requests. This means that components $\tau_{\text {req }}(3 \mathrm{P}, k)$ and $\tau_{\text {resp }}(k, 3 \mathrm{P})$ are predominantly determined by propagation delays between the $3 \mathrm{P}$ agent and the corresponding DMA.

Obviously, the obtained results can be generalized (by multiplication) to protocol procedures with multiple queries and responses, as well as to the multi-round negotiation.

\subsection{Simulation and results}

Simulations were carried out using the network simulator NS2 and its associated tools for animation and analysis. Figure 4 presents simulated topologies of the two realistic networks, BTEurope and BTUSA, obtained from [24]. They are parts of the worldwide IP backbone of the British telecommunication operator BT Group. 


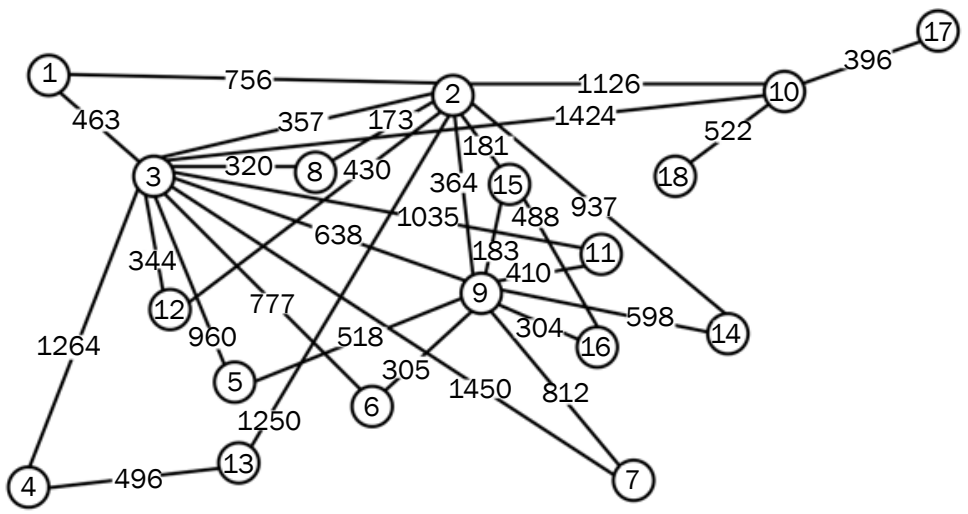

a) BTEurope

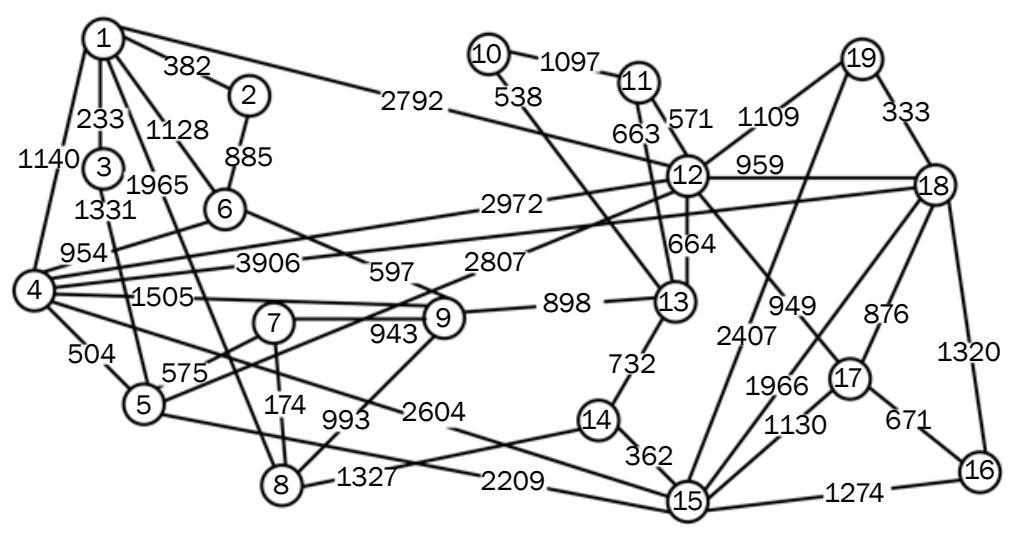

b) BTUSA

Figure 4 - Simulated network topologies

(the numbers on the links represent air distance in kilometres)

Each administrative domain with its DMA is approximated as a virtual node, which is interconnected with the other domains (virtual nodes) by external links [25, $26]$. The original NS2 Distance Vector routing module is used, and equal costs of all links (cost=1) are adopted, which means that the traffic is routed over paths with the smallest number of hops. The reserved bandwidth for signalling traffic on each link is $100 \mathrm{Mb} / \mathrm{s}$. Error-free and loss-free transmission were supposed due to the fact that signalling traffic should be transferred with absolute QoS guarantees.

Request and response times are calculated as sums of propagation delays and processing delays. Link propagation delay is determined as $\tau_{\text {prop }}=\frac{l}{v}$, where $l$ represents link length and $v$ is light propagation speed through fibre (approximately $2 \cdot 10^{8} \mathrm{~m} / \mathrm{s}$ ). Link length $l$ is determined from air distance dist (indicated in Figure 4) according to the ITU-T recommendation G.826 [27], as presented in Table 1.

The signalling requirements of the proposed model and a dynamic distributed model are compared. Such a distributed model assumes that each DMA initiator controls the negotiation process along the E2E path.
As already mentioned, in the proposed model the processing complexity is transferred to the SEA, while DMAs perform simple packet forwarding. In the distributed model each DMA performs rather complex packet processing. The values of processing times $\tau_{\text {proc }}$ have been adopted according to [22] and [28]. In the 3P-based model $\tau_{\text {proc }}$ equals $10 \mathrm{~ms}$ in the SEA and 1 $\mathrm{ms}$ in each DMA. In the distributed model, $\tau_{\text {proc }}$ in each DMA equals $10 \mathrm{~ms}$.

Performances are evaluated in terms of time needed to establish the service in a single round and in multiple rounds and influence of the number of transit domains to service negotiation time. The signalling message length equals 1,000 bytes. In the centralized model, it is supposed that the $3 \mathrm{P}$ agent is collocated

Table 1 - Determining actual link length based on air distance [27]

\begin{tabular}{|c|c|c||}
\hline Air distance dist & $\begin{array}{c}\text { Multiplying } \\
\text { factor }\end{array}$ & $\begin{array}{c}\text { Link length } \\
l\end{array}$ \\
\hline \hline dist $<1,000 \mathrm{~km}$ & 1.5 & 1.5 dist \\
\hline $1,000 \mathrm{~km} \leq$ dist $<1,200 \mathrm{~km}$ & - & $1,500 \mathrm{~km}$ \\
\hline dist $\geq 1,200 \mathrm{~km}$ & 1.25 & 1.25 dist \\
\hline
\end{tabular}


with one of the DMAs in the network. Four cases have been analysed with different locations of the 3P agent, as summarized in Table 2. The sequence numbers of the nodes correspond to the numeration in Figure 4.

Table 2 - Location of the 3P agent in the simulated networks

\begin{tabular}{|l|c|c|c|c|}
\hline \multirow{2}{*}{ Network } & \multicolumn{4}{|c|}{ Location } \\
\cline { 2 - 5 } & 1 & 2 & 3 & 4 \\
\hline \hline BTEurope & Node 2 & Node 14 & Node 3 & Node 7 \\
\hline BTUSA & Node 13 & Node 9 & Node 4 & Node 18 \\
\hline
\end{tabular}

Table 3 presents the average service negotiation times, assuming a single query-response transaction, for both distributed and 3P-based models. The service negotiation time in the distributed model highly depends on the number of domains, network topology as well as on the link latency characteristics. It should be noticed that the service negotiation time highly affects the network resource utilization, because resource reservation should be performed during negotiation. Long-lasting E2E signalling transactions are particularly undesirable if negotiation does not succeed. For example, if one domain on the path rejects the service request, other domains, which are willing to accept the agreement, waste resources due to keeping reservations during negotiation.

The advantage of the proposed model is a consequence of the fact that complex calculations are transferred to the 3P agent. Service negotiation time can be affected by the location of the 3P agent, but even in the worst case scenario (Location 4 in Table 3) the negotiation time is much shorter than in the distributed model. For further analysis we adopt the location of 3P agent that provides the shortest average service negotiation time, i.e. Location 1 from Table 2 and Table 3.

Figure 5a presents the average service negotiation time assuming a multi-round negotiation due to failed negotiation attempts. It is assumed that $20 \%$ of SLAs in each network need to be re-negotiated, i.e. the contracts are successfully established in the second or third round. Service negotiation time is affected by the network size and topology, but the proposed 3P-based model significantly outperforms the distributed model, in the sense of reduced latency and less dependence on the number of attempts.

Figure $5 b$ depicts the average service negotiation time as a function of the number of transit domains. While in the distributed model, the service establishment time significantly increases with the number of transit domains, in the 3P-based model it remains almost constant, which is also in accordance with Equation 2.

\section{SEA PROTOTYPE DEVELOPMENT \\ 5.1 Implemented modules and software structure}

The SEA prototype has been developed for the Windows environment using object-oriented design and $\mathrm{C}++$ programming language. Regarding functional architecture of the SEA described in Section 3,

Table 3 - Average service negotiation time (single signalling transaction) [ms]

\begin{tabular}{||c|c|c|c|c|c||}
\hline \multirow{2}{*}{ Network } & \multirow{2}{*}{ Distributed model } & \multicolumn{4}{|c||}{ 3P-based model } \\
\cline { 3 - 6 } & & Location 1 & Location 2 & Location 3 & Location 4 \\
\hline \hline BTEurope & 62.86 & 26.96 & 27.17 & 27.83 & 42.38 \\
\hline BTUSA & 76.40 & 39.74 & 44.54 & 45.62 & 54.42 \\
\hline
\end{tabular}
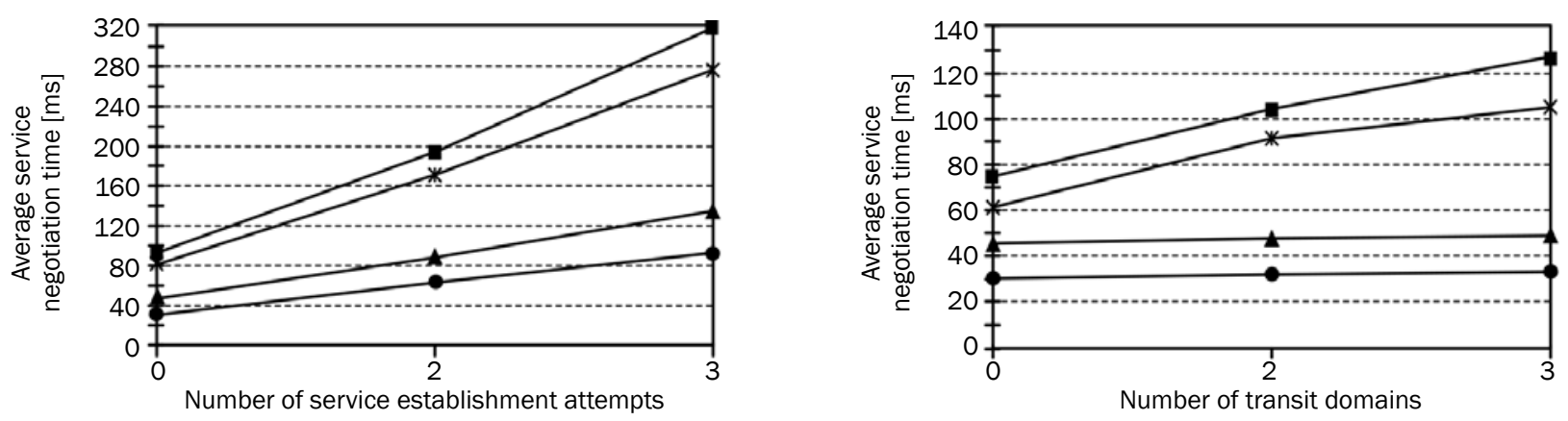

\begin{tabular}{ll|}
$\longrightarrow \rightarrow$ BTEurope (3P-based model) & $\rightarrow-$ BTEurope (Distributed model) \\
$\longrightarrow \longleftarrow$ BTUSA (3P-based model) & - BTUSA (Distributed model) \\
\hline
\end{tabular}

a)

b)

Figure 5 - Average service negotiation time: (a) multi-round negotiation, and (b) as a function of the number of transit domains 


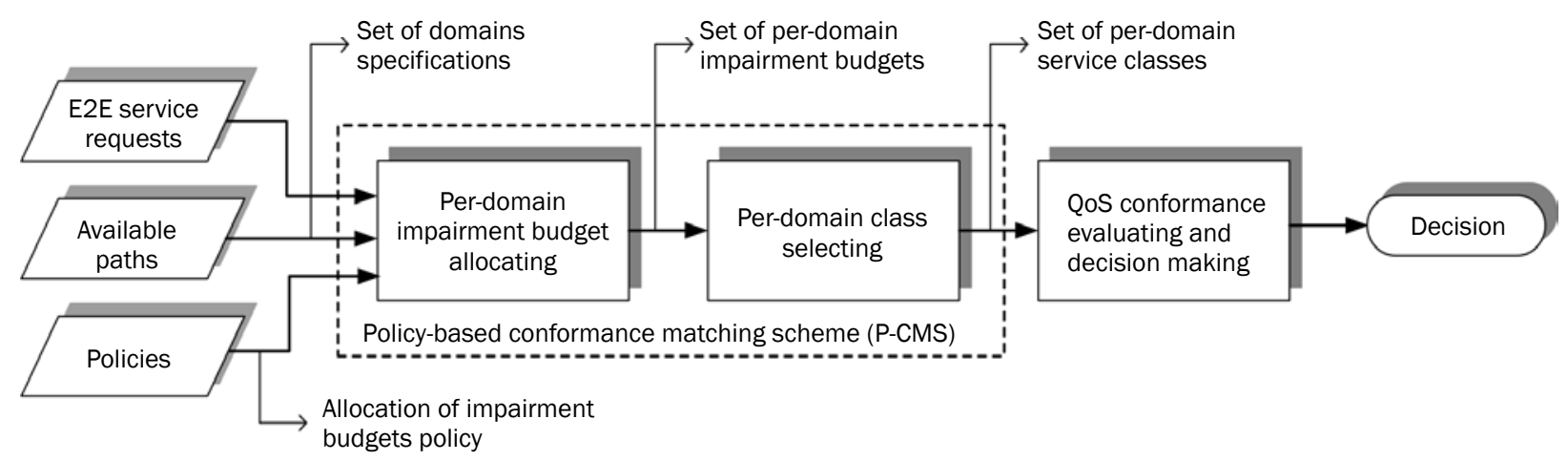

Figure 6 - SEA prototype: Service negotiation flowchart

our prototype consists of the following modules: Request interpreter and policy selector, Class mapper, QoS conformance evaluator, and Decision maker. The definition of E2E service request and selection of the appropriate policy for the allocation of performance impairment budgets are performed manually. Routing information should be signalled to the 3P agent in order to identify transit providers on each path (e.g. from BGP, number of autonomous systems) and their performance. The list of available E2E paths is obtained from the global resource state table. Figure 6 depicts the service negotiation flowchart.

The Policy-based Conformance Matching Scheme (P-CMS) is used for class mapping. We further describe the basic principles of the scheme, while a detailed description and evaluation can be found in [21]. Assume that E2E path consists of $n$ domains. The P-CMS performs: (1) allocation of per-domain performance impairment, and (2) per-domain class selection. The algorithm automatically selects a class in each domain $d(d=1,2, \ldots, n)$ on the basis of the following input parameters: (1) specification of domains on the path, (2) service request for domain $d$, and (3) selected policy for allocating impairment budgets.

The algorithm for allocation of performance impairment budgets is depicted in Figure 7. Assume that SEA defines $M$ performance metrics. Impairment budget $I B_{j}^{d}$ for domain $d$ and performance metric $j(j=1,2, \ldots, M)$ is calculated according to:

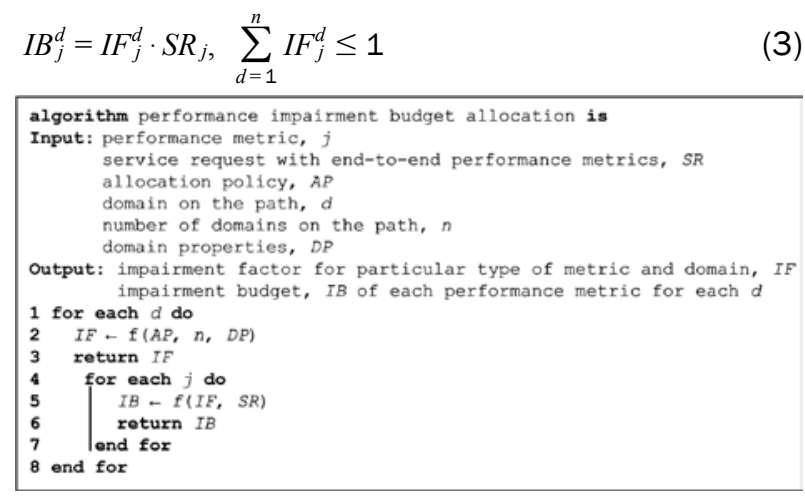

Figure 7 - Allocation of performance impairment budgets where $I F_{j}^{d}$ represents the impairment factor for domain $d$ and metric $j$, while $S R_{j}$ represents E2E request for metric $j$. In general, $I F_{j}^{d}$ is determined as a product of representative factors, which reflect relevant shortterm and long-term domain properties for metric $j$, respectively. A number of specific polices can subsequently be derived from such a generic form, depending on the specific administrative constraints, domain attributes, and resource utilization [21].

After calculation of impairment budgets, the P-CMS performs per-domain class selection, as depicted in Figure 8. For that purpose, the P-CMS calculates degree of correspondence $D C_{j k}^{d}$ between the required and the offered value for metric $j$, for each of $K_{d}$ service classes available in domain $d$, i.e.:

$D C_{j k}^{d}=\frac{I B_{j}^{d}}{I B_{j k}^{d}}=I F_{j}^{d} \cdot \frac{S R_{j}}{I B_{j k}^{d}}, \quad k=1, \ldots, K_{d}$

After all the classes have been analysed, per-domain degree of correspondence for class $k$, $D C_{k}^{d}$, is calculated according to:

$D C_{k}^{d}=\frac{1}{M} \sum_{j=1}^{M} D C_{j k}^{d}, k=1, \ldots, K_{d}$

Class $k$ is selected if:

$\left|1-D C_{k}^{d}\right|=\min \left\{\left|1-D C_{1}^{d}\right|, \ldots,\left|1-D C_{K_{d}}^{d}\right|\right\}$

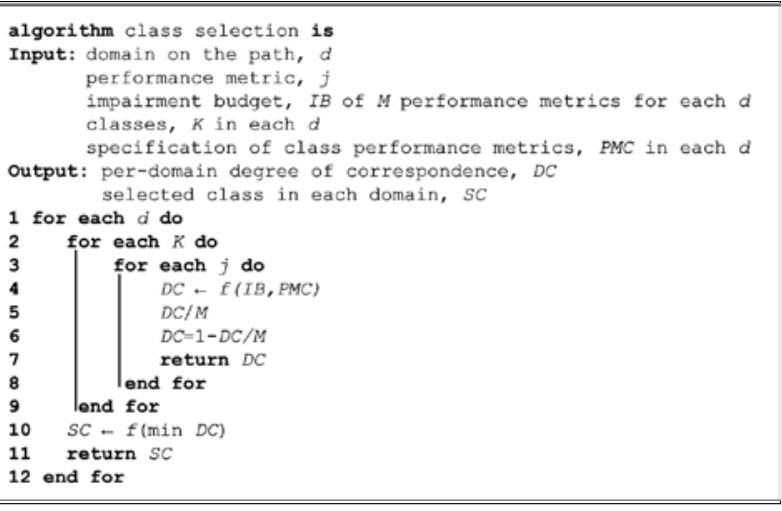

Figure 8 - Per-domain class selection 
i.e. the selected class is the one with the degree of correspondence closest or equal to 1 . If class $k$ is selected among $K_{d}$ candidates, per-domain degree of correspondence $D C^{d}$ is:

$D C^{d}=D C_{k}^{d}$

After per-domain class selection and calculation of per-domain degrees of correspondence $D C^{d}$ for $d=1$, $2, \ldots, n$, QoS conformance is evaluated and the decision about the acceptability of the offered service is made, as described in Figure 9.

QoS conformance is evaluated by means of overall degree of correspondence for the particular service request $O D C(S R)$ :

$O D C(S R)=\frac{\left(\sum_{d=1}^{n} D C^{d}\right)}{n}$

Service request $S R$ is accepted if:

$O D C(S R) \geq T_{\text {conf }}, \quad T_{\text {conf }} \leq 1$

where $T_{\text {conf }}$ represents a predefined conformance threshold that determines the acceptability level of the offered service. There are three possibilities: (1) service request is acceptable; (2) renegotiation is activated by examining another available E2E path, or (3) service request is rejected if there are no available paths.

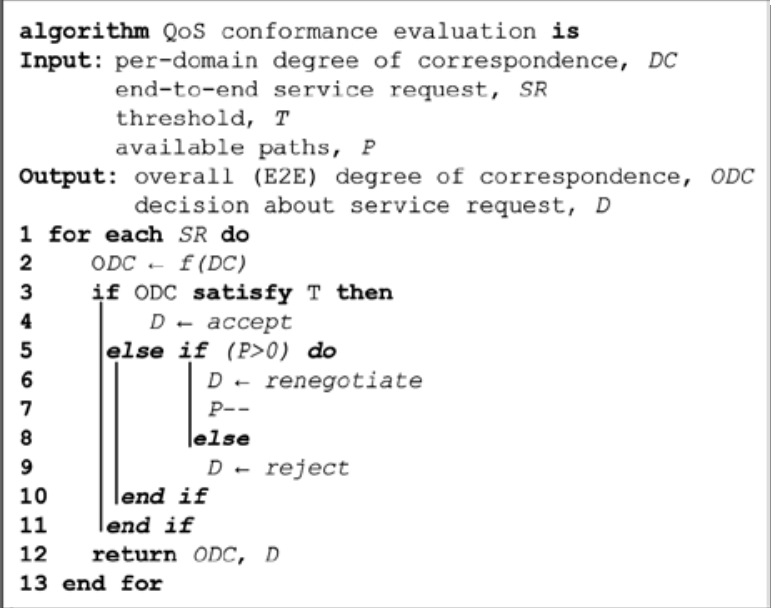

Figure 9 - QoS conformance evaluation and decision making

\subsection{Performance evaluation}

We examined the prototype performance in terms of the overall processing time, average per-request processing time, and average CPU utilization for handling simultaneous arrival of multiple E2E service requests. Tests cover the arrival and interpretation of service requests, execution of the P-CMS algorithm, QoS conformance evaluation and decision making, and preparation of configuration parameters for the appropriate DMAs. Path and domains specifications are available from the global resource state table, supposing the BTEurope topology from Figure 4. Each test includes paths with approximately the same number of one, two and three transit domains.

The number of service requests was varied in the range from 50 to 500 , using computing platform Intel i7-5500U CPU at $2.40 \mathrm{GHz}, 8 \mathrm{~GB}$ RAM, and Windows 10 operating system. Tests were performed by means of the Microsoft Process Explorer [29]. Each test was carried out ten times and the results were averaged.

The obtained test results are summarized in Figures 10 and 11 . The overall processing time almost linearly increases with the increasing number of service requests, while mean time to process a single request remains nearly constant. The average CPU utilization slightly increases with the number of requests. The obtained results indicate feasibility of the proposed approach, especially with respect to scalability. Certainly, additional processing requirements might depend on the applied inter-domain routing scheme and the frequency of updating the global resource state tables.

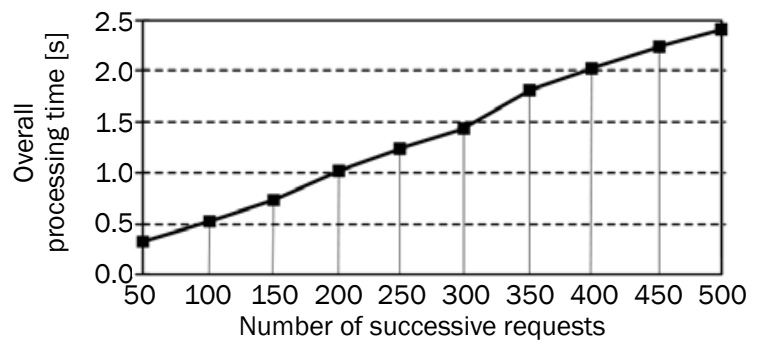

a) Overall processing time

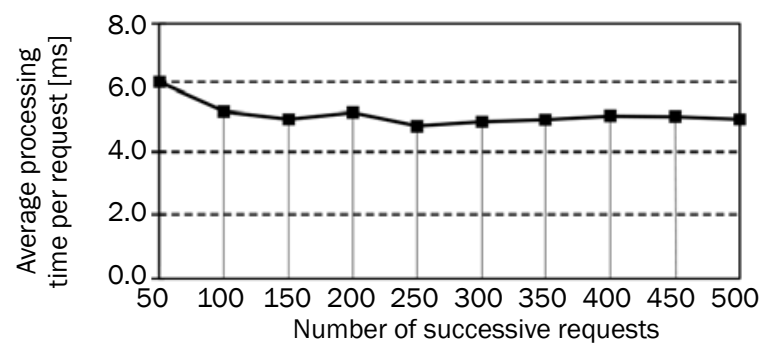

b) Average per-request processing time

Figure 10 - Processing time as a function of the number of successive E2E service requests

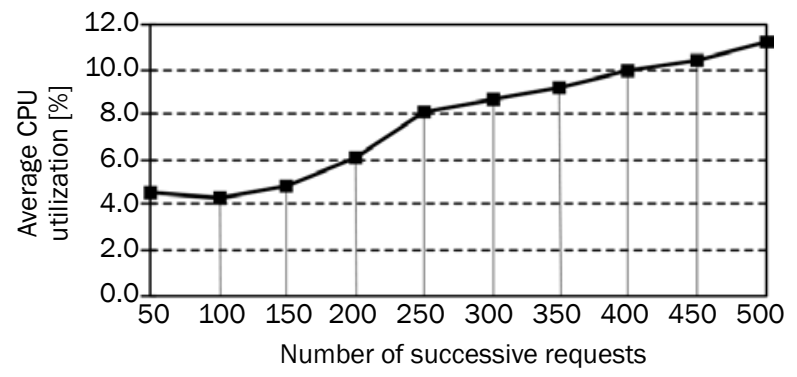

Figure 11 - Average CPU utilization as a function of the number of successive E2E service requests 


\section{CONCLUSION}

Functional architecture of the 3P-based service establishment agent, which controls E2E service negotiation process and establishes the associated SLAs has been proposed. The advantages of the given proposal are as follows.

The functional architecture is highly modular, thus allowing implementation of different algorithms for allocation of performance impairment budgets, per-domain class selection and QoS conformance evaluation. In addition, sets of different algorithms may coexist together with the set of management policies that allow for their automated selection.

The architecture is completely independent of per-domain QoS models and associated definitions of service classes. There is no need to develop specialized inter-domain interfaces or to redesign providers' networks in any other way. The only prerequisite is the existence of per-domain management agents (DMAs).

Simulation results show that the proposed SEA model significantly outperforms the distributed model in terms of QoS signalling requirements. Service negotiation times are shorter, and they only weakly depend on the number of transit domains. Additional advantage is the avoidance of class mapping at the domains boundaries.

In the prototype development process, a policy-based solution for mapping of service classes was implemented, namely the P-CMS. The performance evaluation shows that the processing requirements introduced by the P-CMS are not severe, even for general purpose processors. Scalability can be additionally enhanced by physical implementation of particular SEA functions in a distributed manner, while preserving logically centralized management. However, the benefit of the SEA approach in comparison with the cooperative approach is the lack of need to pre-establish long-term consensus of involved domains about technical prerequisites for achieving QoS-based interconnection. Thus, service establishment can be highly dynamic, without technical limitations affecting service lifecycle.

One of the potential directions of the future research refers to the coexistence of multiple, interconnected 3P agents (each with a SEA), which would cover larger areas and provide for E2E QoS when a service has to cross considerable number of domains. A hierarchical organization of interconnected $3 \mathrm{P}$ agents may contribute to improving scalability and reliability of the service establishment.

\section{ACKNOWLEDGEMENT}

This research was partially funded by a grant (No. TR 32025) from the Ministry of Education, Science and Technological Development of Serbia.
Dr SLAVICA BOŠTJANČIČ RAKAS, naučni saradnik ${ }^{1}$

E-mail: slavica.bostjancic@institutepupin.com Prof. dr MIRJANA STOJANOVIĆ ${ }^{2}$

E-mail: m.stojanovic@sf.bg.ac.rs

${ }^{1}$ Univerzitet u Beogradu, Institut Mihajlo Pupin Volgina 15, 11060 Beograd, Srbija

2 Univerzitet u Beogradu, Saobraćajni fakultet Vojvode Stepe 305, 11000 Beograd, Srbija

\section{CENTRALIZOVANI MODEL ZA USPOSTAVLANJE E2E KOMUNIKACIONIH SERVISA POSREDSTVOM UPRAVLJAČKIH AGENATA}

\section{KRATAK SADRŽAJ}

$U$ radu je predstavljen centralizovan pristup uspostavljanju E2E (End-to-End) telekomunikacionih servisa pomoću agenata za upravljanje. Predložena je modularna arhitektura agenta za uspostavljanje servisa (Service Establishment Agent, SEA), koji je zasnovan na posredničkom pristupu. SEA upravlja procesom ugovaranja servisa između domena koji čine E2E putanju. Komunikacija sa lokalnim agentima za upravljanje domenima se vrši preko agenta za signalizaciju. SEA takođe prima i interpretira zahteve za E2E servise, vrši selekciju E2E putanje, preslikavanje klasa servisa između domena na putanji, kao i ocenu usklađenosti ponuđenog servisa sa zahtevanim. Osim toga, omogućava i implementaciju različitih algoritama za prethodno nabrojane funkcije, kao i selekciju i kombinovanje tih algoritama na osnovu unapred definisanih politika upravljanja. Rezultati simulacije pokazuju da je predloženi model, u pogledu vremena potrebnog za ugovaranje servisa, značajno bolji od distribuiranog modela. Razvijen je i SEA prototip odnosno rešenje za preslikavanje klasa servisa zasnovano na politikama upravljanja. Rezultati ispitivanja su pokazali da su zahtevi za procesiranje višestrukih, istovremenih zahteva za servis umereni, a glavna prednost predloženog pristupa jeste to što nije potreban dugoročni dogovor između provajdera o tehničkim parametrima za realizaciju interkonekcije telekomunikacionih mreža. Arhitektura agenta SEA je u potpunosti nezavisna od mehanizama kvaliteta servisa koji su na raspolaganju u domenima na putanji.

\section{KLUČNE REČI}

centralizovano upravljanje; ugovaranje između provajdera; kvalitet servisa; uspostavljanje servisa;

\section{REFERENCES}

[1] Strobel 0. Communication in transportation systems. IEEE Communications Surveys and Tutorials. Hershey, PA, USA: IGI Global; 2013.

[2] Garofalaki Z, Kallergis D, Katsikogiannis G, Douligeris C. A Policy aware Model for Intelligent Transportation Systems. Proceedings of the $1^{\text {st }}$ International Balkan Conference on Communications and Networking, 30 May - 2 June 2017, Tirana, Albania; 2017.

[3] Kamienski CA, Sadok D. The Case for Interdomain Dynamic QoS-Based Service Negotiation in the Internet. Computer Communications. 2004;27(7): 622-637.

[4] Jacobs P, Davie B. Technical Challenges in the Delivery of Interprovider QoS. IEEE Communications Magazine. 2005;43(6): 112-118. 
[5] Matos F, Matos A, Simões P, Monteiro E. Provisioning of Inter-Domain QoS-Aware Services. Journal of Computer Science and Technology. 2015;30(2): 404-420.

[6] Pouyllau H, Douville R. End-to-End QoS Negotiation in Network Federations. In: Proceedings of the IEEE/IFIP Network Operations and Management Symposium Workshops (NOMS), 19 - 23 April 2010, Osaka, Japan; 2010. p. 173-176.

[7] Yin H, Jiang Y, Lin C, Luo Y, Liu Y. Big Data: Transforming the Design Philosophy of Future Internet. IEEE Network. 2014;28(4): 14-19.

[8] You L, Motta G, Sfondrini N. SLM as a Third Party Service in Cloud Environment: A Reference Framework. In: Proceedings of the IEEE International Conference on Services Computing (SCC), 2015, 27 June - 2 July 2015, New York, NY, USA; 2015. p. 640-647.

[9] Stanik A. Service level agreement mediation, negotiation and evaluation for cloud services in intercloud environments. PhD thesis. Faculty for Electrical Engineering and Computer Science, Technical University of Berlin; 2016. Available from: https://depositonce. tu-berlin.de/handle/11303/5443 [Accessed 15 March 2018].

[10] Agiatzidou E, Courcoubetis C, Dugeon O, Johansen F-T, Stamoulis GD. Inter-Domain Coordination Models. In: Becvar Z, Bestak R, Kencl L. (eds.) Proceedings of the NETWORKING 2012, 21 - 25 May, Prague, Czech Republic; 2012. p. 113-120.

[11] Houidi ZB (Ed.). Detailed specification of ETICS components for the inter-carrier service delivery. ETICS: economics and technologies for inter-carrier services. Deliverable D5.8, 2013. Available from: https://www. ict-etics.eu/publications/deliverables.html [Accessed 15 March 2018].

[12] Bruns G, Cortes M. A Hierarchical Approach to Service Negotiation. In: Proceedings of the 2011 IEEE International Conference on Web Services, 4 - 9 July 2011, Washington, DC, USA; 2011. p. 460-467.

[13] O'Droma M, Ganchev I. The Creation of a Ubiquitous Consumer Wireless World Through Strategic ITU-T Standardization. IEEE Communications Magazine. 2010;48(10): 158-165.

[14] Atanasov I, Pencheva E, Dimova R. Toward Open Service Access to Policy and Charging Control in Evolved Packet System. Telecommunication Systems. 2015;59(3): 365-380.

[15] lqbal HA. A logically centralized approach for control and management of large computer networks. PhD thesis. University of Pittsburgh; 2013. Available from: http://d-scholarship.pitt.edu/17059/ [Accessed 15 March 2018].

[16] Stojanovic M, Bostjancic Rakas S, Acimovic-Raspopovic V. End-to-End Quality of Service Specification and Mapping: The Third Party Approach. Computer Communications. 2010;33(11): 1354-1368.

[17] Mali BJ, Ninkovic NM, Stojanovic MD, Savic GI. Service Class Mapping Based on Integer Programming Algorithm in the Third Party Agent. Telfor Journal. 2015;7(1): 2-7.

[18] Ninkovic N, Mali B, Stojanovic M, Savic G. Multi-Objective Third-Party Approach for Service Class Mapping Among Multiple Providers in the Internet. Elektronika Ir Elektrotechnika. 2015;21(2): 80-84.

[19] Ding J. Advances in network management. New York: Auerbach Publications; 2009.

[20] Martini B, Paganelli F. A Service-Oriented Approach for Dynamic Chaining of Virtual Network Functions over Multi-Provider Software-Defined Networks. Future Internet. 2016;8(2): 1-21.

[21] Stojanovic M, Bostjancic Rakas S. Policies for Allocating Performance Impairment Budgets Among Multiple IP Providers. International Journal of Electronics and Communications (AEÜ). 2013;67(3): 206-216.

[22] International Telecommunication Union - Telecommunication Standardization Sector (ITU-T). Recommendation Y.1542. Framework for achieving end-to-end IP performance objectives. Geneva: ITU-T; 2010.

[23] Mingozzi E, Stea G, Callejo-Rodriguez MA, Enríquez-Gabeirasb J, García-de-Blasb G. RamónSalquerob FJ et al. EuQoS: End-to-End Quality of Service Over Heterogeneous Networks. Computer Communications. 2009;32(12): 1355-1370.

[24] The University of Adelaide. The Internet Topology Zoo. Available from: http://www.topology-zoo.org/index. html [Accessed 15 March 2018].

[25] Gao Z, Naser H. A Virtual Node-Based Shared Restoration Scheme in Multi-Domain Networks. In: Proceedings of the Canadian Conference on Electrical and Computer Engineering - CCECE '09, 3 - 6 May 2009, St. John's, NL, Canada. IEEE; 2009. p. 847-851.

[26] [26] Stojanovic M, Miladic S, Markovic G. A Hybrid Method for Signalling Transport in GMPLS Control Plane. Elektronika Ir Elektrotechnika. 2016;22(3): 24-28.

[27] International Telecommunication Union - Telecommunication Standardization Sector (ITU-T). Recommendation G.826. End-to-end error performance parameters and objectives for international, constant bit-rate digital paths and connections. Geneva: ITU-T; 2002.

[28] Ramaswamy R, Weng N, Wolf T. Characterizing network processing delay. In: Proceedings of the IEEE Global Communications Conference (GLOBECOM), 29 November - 3 December 2004, Dallas, Texas, USA. IEEE; 2004. p. 1629-1634.

[29] Microsoft. Process Explorer v16.21. Available from: https://technet.microsoft.com/en-us/sysinternals/ processexplorer.aspx [Accessed 15 March 2018]. 